\title{
A 'semi-closed' recirculating system for the in situ study of feeding and respiration of benthic suspension feeders*
}

\author{
MARTA RIBES ${ }^{1,2}$, RAFEL COMA ${ }^{1,3}$, JOSEP-MARIA GILI $^{1}$, ARMIN SVOBODA $^{4}$, \\ AGUSTÍ JULIÀ ${ }^{1}$ and JORDI PARERA ${ }^{1}$ \\ ${ }^{1}$ Institut de Ciències del Mar (CSIC), Passeig Joan de Borbó s/n, 08039 Barcelona, Spain. \\ ${ }^{2}$ Hawaii Institute of Marine Biology, PO Box 1346, Kaneohe, Hawaii 96744, USA. \\ ${ }^{3}$ Departament d’Ecologia, Universitat de Barcelona. Avda Diagonal 645, 08028 Barcelona, Spain. \\ ${ }^{4}$ Ruhr Universität Bochum, Lehrstuhl fur Spezielle Zoologie, D-44800 Bochum, Germany
}

\begin{abstract}
SUMMARY: Suspension feeding is one of the most widespread feeding strategies among benthic organisms. However, natural feeding ecology and energetics of benthic suspension feeders are poorly known. The scarcity of field methods, apparatus and protocols that facilitate obtention of reliable in situ data has contributed to this lack of knowledge. A detailed description of an improved semi-closed recirculating system as well as the experimental set up is provided for the study of energetics in benthic suspension feeders. The system, completely submersible and surface-independent, allows us to assess oxygen concentration changes and feeding rates under natural conditions. Methodological examinations are conducted to investigate: a) the circulation of the water within the chamber; b) the time required for the flushing pump to entirely renew the volume of water of the incubation chambers; c) the behavior of the species within the chambers; d) the time of acclimation to the chamber conditions for the different species; e) the maximum decrease in oxygen concentration without affecting respiration rate; $f$ ) the time required to detect changes in concentration of the natural food sources. The system and experimental protocol is tested with species from three representative phyla, Porifera, Cnidaria and Tunicata.
\end{abstract}

Key words: suspension feeding, methods, recirculating system, respiration, natural feeding.

\section{INTRODUCTION}

Suspension feeding is one of the most widespread feeding strategies among benthic organisms. It can be observed in organisms from several different taxa such as Porifera, Cnidaria, Bryozoa, Brachiopoda, Annelida (Polychaeta), Mollusca (Bivalvia), Echinodermata, Crustacea and Tunicata. The main advantage of suspension feeding strategy is an energetic one. No energy is spent in searching for food in passive suspension feeders, and, even in

\footnotetext{
*Received August 4, 2000. Accepted October 6, 2000.
}

active filter feeders, the cost of pumping has been estimated to be very low $(0.3-4 \%$ of the total metabolic expenditure for different taxa, Riisgård and Larsen, in press). The main handicap is that suspension feeders can not choose the amount and quality of food they have access to. Therefore, it has long been postulated that most suspension feeders are non-selective (Jørgensen, 1966), and that their diet is primarily controlled by structural constraints (Rubenstein and Koehl, 1977). If this is so, then, within morphological limitations, the composition of the ingested material should be similar to that of suspended material in the surrounding water. How- 
ever, most feeding studies have been carried out with restricted or artificial diets (e.g., Leversee, 1976; Lasker, 1981) or through gut contents analysis which underestimates small soft-bodied organisms that leave no recognizable remains (e.g., Coma et al., 1994). These studies do not reveal which organic fractions are being used as food sources and in what proportions.

Microbial communities are the main contributors to planktonic communities in terms of biomass (Stoeckner and Antia, 1986) and production (Platt et al., 1983; Burkill et al., 1993). As a consequence, much research has been conducted on the dynamics of these planktonic communities in the water column and their trophic interactions with other groups of plankters (Azam et al., 1983; Sherr and Sherr, 1991). In littoral ecosystems, little work has been completed on the trophic interactions between microbial communities and benthic macroinvertebrates. However, recent studies have shown that the role of bacteria, protozoa and phytoplankton in the diet of benthic suspension feeders other than bivalves appears to be higher than previously thought (e.g., Petersen and Riisgård, 1992; Pile et al., 1996, 1997; Ribes et al., 1998, 1999a,b). These studies reveal that one of the less known aspects of the biology of benthic suspension feeders is their natural diets. Despite the little knowledge about feeding of benthic suspension feeders under natural condition, several recent studies suggest an important impact of benthic suspension feeders on planktonic populations (Ayukai, 1995; Gili and Coma, 1998) and, in some special environments, benthic suspension feeders have been suggested to be able to control the dynamics of planktonic populations (e.g., Cloern, 1982). These studies indicate that the feeding ecology of benthic suspension feeders may represent an important step to understanding functioning of littoral ecosystems.

Energetic studies contribute to the comprehend of the dynamics of benthic organisms especially in areas with important seasonal variations of the main environmental factors (Coma et al., 1998). Within the framework of an energetic approach to the study of the dynamics of benthic organisms, respiration constitutes one of the largest fractions of the energy demand of benthic organisms. Respiration can be defined as an energy producing process in living systems that degrade organic matter. The energy released during this degradation is used by the living system to achieve the goals of its survival strategy (Lucas, 1996). Physical factors, including tempera- ture, salinity, ambient oxygen concentration, water flow, and trophic effects, including particle size, filtration activity and food concentration, have been suggested as important factors affecting respiration (Shumway, 1982; Jørgensen, 1966; Sebens, 1987; Patterson et al., 1991; Lucas, 1996; Riisgård and Larsen, in press). Most respiration studies have been performed under laboratory conditions allowing isolation of the effects of the different parameters that affect respiration. Although laboratory studies have made an important contribution to understanding the physical and biological factors that affect respiration, it is difficult to extrapolate laboratory estimates of respiration rates to the field. The main constraint of in situ studies is that they cannot isolate the effects of the different parameters that are affecting respiration, but they do provide realistic estimates of the processes because they are conducted with organisms under natural conditions.

One of the most important limitations in order to progress in the knowledge of the natural feeding and energetics of benthic suspension feeders is the scarcity of field methods, apparatus and protocols that facilitate obtention of reliable in situ data. Some methods devoted to examine the metabolism of invertebrates (mainly respiration) in the field have undergone significant development and modification during the past years (e.g., Svoboda and Ott, 1983; Tengberg et al., 1995). However, advance in the study of natural diet has been mainly constrained by the large volume required for sample analysis and by the length of time required to evaluate potential food sources. The improvement of flow cytometry and related techniques to examine natural microbial populations has occurred during the last decade, providing an exponential rise in this field due to the substantial reduction in the volume of sample required and in the effort of examination (e.g., Gasol and del Giorgio, 2000). This technical improvement has allowed the scientific community to realize the importance of pico- $(0.2-2 \mu \mathrm{m})$ and nanoplankton (2-20 $\mu \mathrm{m})$ in marine ecosystems, now considered to be the main contributors to planktonic communities in terms of biomass and production (Tremblay and Legendre, 1994).

Recent field studies on the natural diet of several sessile benthic suspension feeders suggest that these organisms feed on a wider spectrum of prey type and size than previously recognized by laboratory experiments (Gili and Coma, 1998). A field methodology to study the energetics of benthic suspension feeders should account for the assessment of the 
entire range of potential prey, which includes dissolved organic carbon and all sources of particulate organic carbon, both live (i.e. planktonic communities) and detrital. The main goal of this paper was to develop a field technique to obtain reliable samples and to provide an analytical procedure to examine energetics of sessile suspension feeders. Using a combination of oxygen electrodes, pumps and a data logger, we designed a system that solved most of the problems related with closed systems. We report here a detailed description of the system and of the experimental protocol. The system, completely sub- mersible and surface-independent, allows us to assess oxygen concentration variation and feeding rates under natural conditions. The technique was tested with several benthic suspension feeding species from different taxa.

\section{DESCRIPTION OF THE SYSTEM}

A general view of the arrangement of the monitoring unit in the field is shown in Fig. 1A and B. A diagrammatic representation of the system (Fig. 1C)
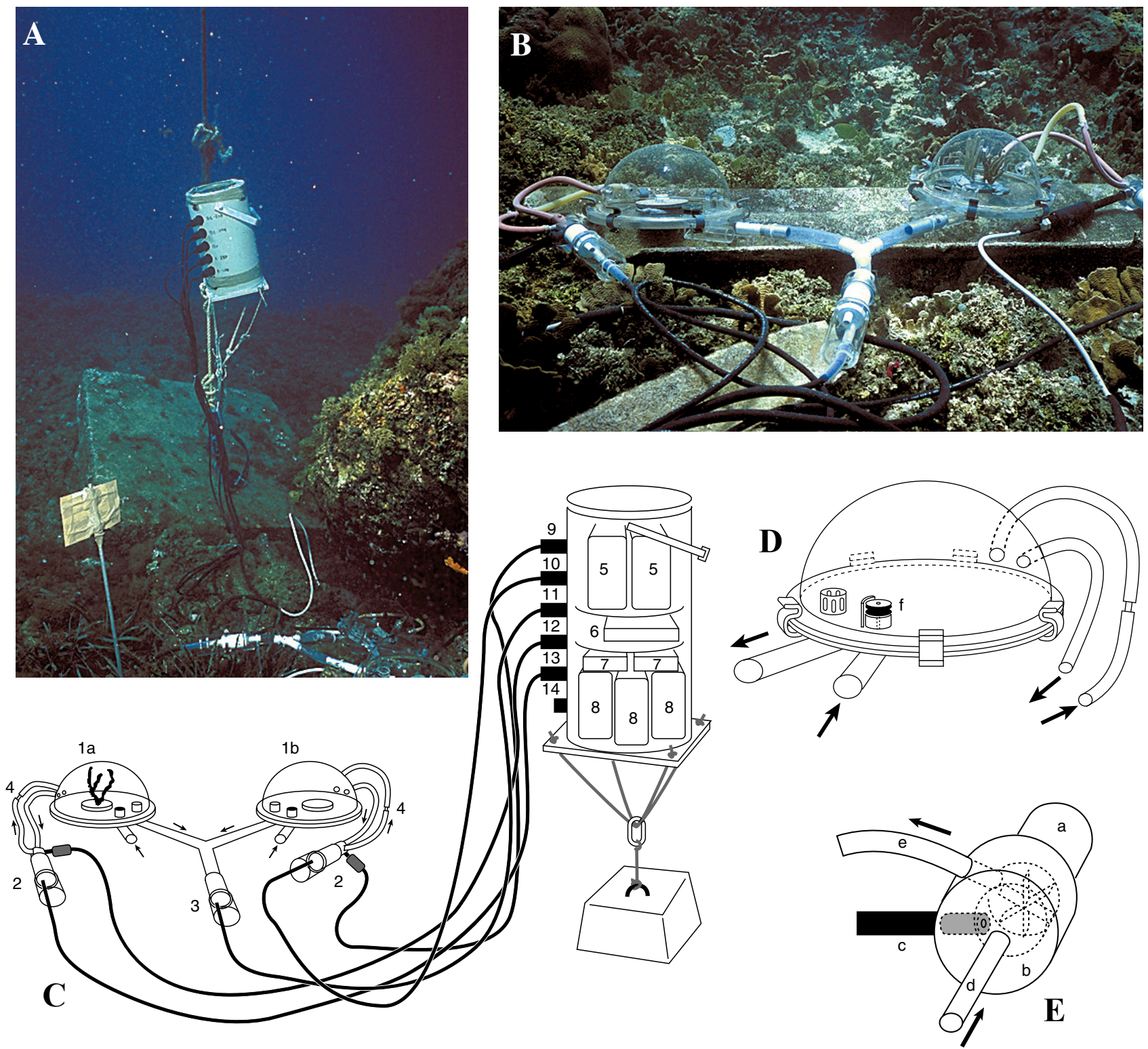

FIG. 1. - Images showing the arrangement of the monitoring units in the field: A.- set-up of the underwater housing containing the electronics. B.- set-up of the chambers, pumps and oxygen probes; C.- Diagrammatic illustration of the whole system. 1a: experimental chamber, $1 \mathrm{~b}$ : control chamber, 2: flow pumps (3 volts), 3: flushing pump (12 volts), 4: PVC tube connecting inlet and outlet apertures of the chambers, 5: electronics of the oxymeters, 6: data logger, 7: voltage-converter, 8: batteries, 9-13 waterproof electrical connectors, 14: ON/OFF switch. D.Illustration of an incubation chamber, f: valve. E.- Illustration of the connection between the pump and the oxygen probe, a: flow pump, b: plexiglas pump head piece, c: oxygen probe, d: chamber outlet connection, e: chamber inlet connection. 
provides a detailed view of the experimental set up and its components. The unit has two major components, the incubation chambers and the underwater housing. Both chambers (1a and 1b in Fig. 1C) are made from hemispherical pieces of transparent Plexiglas (acrylic glass bei Röhn and Hass, Germany; Svoboda, 1978; Svoboda and Ott, 1983), approximately 3 liters in volume and sealed to a flat transparent plexiglas base with a soft O-ring of foam rubber, glued firmly to the rim of the hemisphere. Plastic fasteners with hooks securely anchor the chambers (Fig. 1D). Inlet and an outlet apertures are connected, via PVC and rubber tubing $0.8 \mathrm{~cm}$ in inner diameter (silicone rubber tubing was not used because it is highly permeable to oxygen), to create a closed system. A small submersible electric pump (flow pump designed for caravan cars and boats, 12V DC, with modified head; 2 in Fig. 1C) is placed at the outlet aperture of each chamber. These two pumps operate at $3.3 \mathrm{~V}$. During normal operation, sea water recirculates through the chamber at a flow of $2.4 \mathrm{~cm}^{3} / \mathrm{s}$ (this flow becomes turbulent inside the chamber). Homogeneous mixing takes place within a few minutes. The submersible polarographic oxygen and temperature probe (Clark-type oxygen probe, WTW EO-196) is pressure and temperaturecompensated (Kanwisher, 1959). It is located close to the flow pump propeller to avoid the formation of microgradients. The probe and the pump, joined through a piece of Plexiglas (Fig. 1E), are connected to the underwater housing by 2 meters of underwater cable and through waterproof electrical con- nectors. At the base of each chamber there is an outlet for the flushing ( 3 in Fig. 1C) that allows the water inside the chamber to be automatically changed. The flushing pump, controlled through the data-logger software, removed the water simultaneously from both chambers. An inlet, with a check valve, at the base of each chamber allows water to come in while the flushing pump is working ( $\mathrm{f}$ in Fig. 1D).

The second main component, a cylindrical underwater housing $(70 \times 35 \mathrm{~cm})$, contains the power supply and converters, a data logger, and the electronics of the probes. The power supply is located at the base of the underwater housing and consists of three batteries (Hitachi Sealed lead-acid, $12 \mathrm{~V}$, 6.5Ah, Shin-kobe Electric Machinery Co., Ltd) that provide the power for the three pumps (8 in Fig. $1 \mathrm{C})$. The flushing pump is powered at 12 volts and is activated when there is a preset change in percentage of the initial oxygen concentration in the chamber were the organism is located. The percentage of change in oxygen concentration can be selected through the data logger software.

A voltage-converter system (DC/DC converter) reduce voltage from the general power supply (12 $\mathrm{V})$ to the flow pumps $(3.3 \mathrm{~V})(7 \mathrm{in} \mathrm{Fig.} \mathrm{1C).} \mathrm{The}$ data logger (Tattletale Model 4A, Onset Computer Corporation) with its own battery $(9 \mathrm{~V})$ is located above the batteries and separated from them by a PVC platform (6 in Fig. 1C). Two oxymeters electronics (WTW microprocessor Oxymeter Oxi 196), which process the signal from the oxygen sensors,

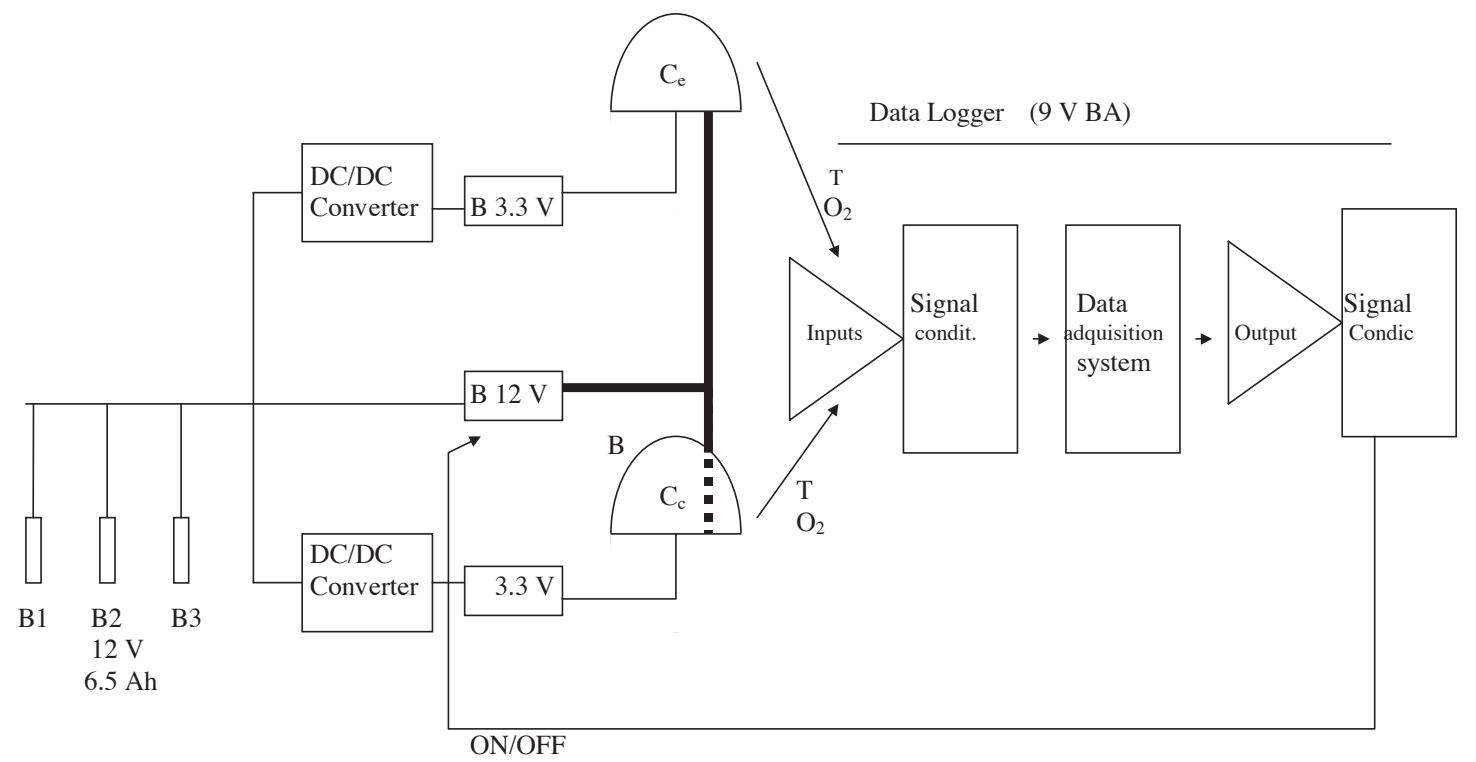

FIG. 2. - Schematics of the electronic parts of the system with detail of the data logger. B1, B2, B3: batteries, DC/DC converter: voltage converter system, B $3.3 \mathrm{~V}$ : flow pumps, B12V: flushing pump. Ce: experimental chamber, Cc: control chamber. Signal condit: conditioner of the analogue outputs. 


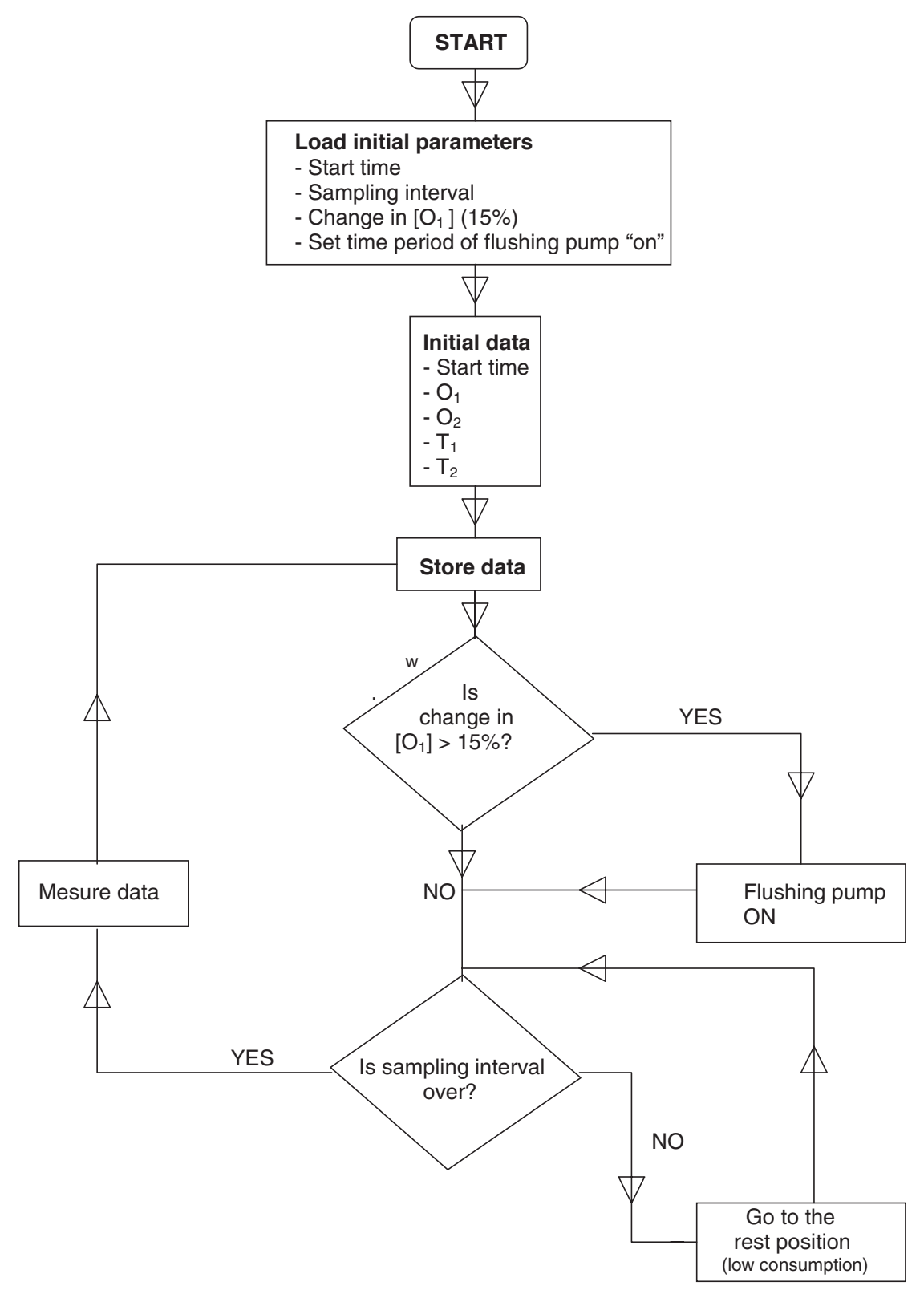

FIG. 3. - Flow diagram of the data logger logics. Subscript 1 refers to change in oxygen $(\mathrm{O})$ and temperature (T) data from the experimental chamber. Subscript 2 refers to data from the control chamber. The program, written in Visual Basic, is provided in Appendix I.

are located on top of the data logger. They are separated from the data logger by another PVC platform (5 in Fig. 1C). The data logger records the measurements of both oxymeters. The software automatically activates the flushing pump when the percentage change in oxygen concentration reaches the preset value. The measurement produced after a $36 \mathrm{sec}-$ onds flushing period becomes the next oxygen concentration of reference.

The data logger, who has 8 analog input and 16 digital output channels, is connected to the electronics of both oxymeters and controls the flushing pump (Fig. 2). Through the data logger software it is possible to determine the start time of measurement collection, the time interval between measurements, the oxygen concentration from the initial concentration that determined the activation of the flushing pump, as well as the time period of flushing. The analogue outputs of the oxygen and temperature meters are fed through a signal conditioner to the data logger where the signal was recorded (Fig. 2). The data logger records the oxygen and temperature measurements of both chambers every 128 seconds. In Appendix I we provide a flow diagram of the data logger functioning is exhibited in Figure 3. The program, written in Visual Basic. 
The upper side of the underwater housing is made of clear acrylic glass. The digital displays of both oxymeter units can be observed. This allows detection of any problem in the functioning of the instrument during the experiments. The cover is sealed with silicone greased O-ring. The chambers and the underwater housing were designed to be handled by SCUBA divers. The underwater housing with the sensors and pumps has a positive buoyancy of about $12 \mathrm{~kg}$. A weight belt was used to provide an slightly negative buoyancy. Then, a diver easily carries it to the experimental site where it was attached to a 50$\mathrm{kg}$ cement flat, allowing us to study the organisms in situ. The device could be left in place for $24 \mathrm{~h}$ to allow us to examine the potential variation in the respiratory activity along the daily cycle.

\section{APPLICATION AND METHODOLOGICAL CONSIDERATIONS}

The system was used to study feeding and respiration in three common Mediterranean benthic invertebrates species: the sponge Dysidea avara, the ascidian Halocynthia papillosa, and the asymbiotic gorgonian Paramuricea clavata. The study was conducted at the Medes Islands Marine Reserve (NW Mediterranean Sea, $\left.42^{\circ} 03^{\prime} N, 3^{\circ} 13^{\prime} \mathrm{E}\right)$. Specimens of the sponge D. avara, the ascidian $H$. papillosa, and the gorgonian $P$. clavata were selected to have a similar size (D. avara: $0.20 \pm 0.003 \mathrm{SD} g$ ash free dry weight (AFDW); H. papillosa: $0.51 \pm 0.14$ SD g AFDW; P. clavata: $0.95 \pm 0.19$ SD g AFDW) to reduce a size effect on the study of both respiration and feeding rates.

D. avara dry weight (DW) was determined by drying at $100^{\circ} \mathrm{C}$ for $24 \mathrm{~h}$, and ash free dry weight (AFDW) was determined by combustion at $500^{\circ} \mathrm{C}$ for 6 h. H. papillosa and P. clavata dry weight was determined by drying at $90^{\circ} \mathrm{C}$ for $24 \mathrm{~h}$ and ash free dry weight by combustion at $450^{\circ} \mathrm{C}$ for 5 hours.

About a month preceding the experiments, several specimens from the three species were removed with a piece of substrate, cleaned from macroepibionts, and placed on artificial supports using inert cement. These specimens were returned to their natural environment close to conspecifics.

Methodological examinations were conducted to investigate: a) the circulation of the water within the chamber; b) the time required for the flushing pump to entirely renew the volume of water of both chambers; c) the behavior of the species within the cham-
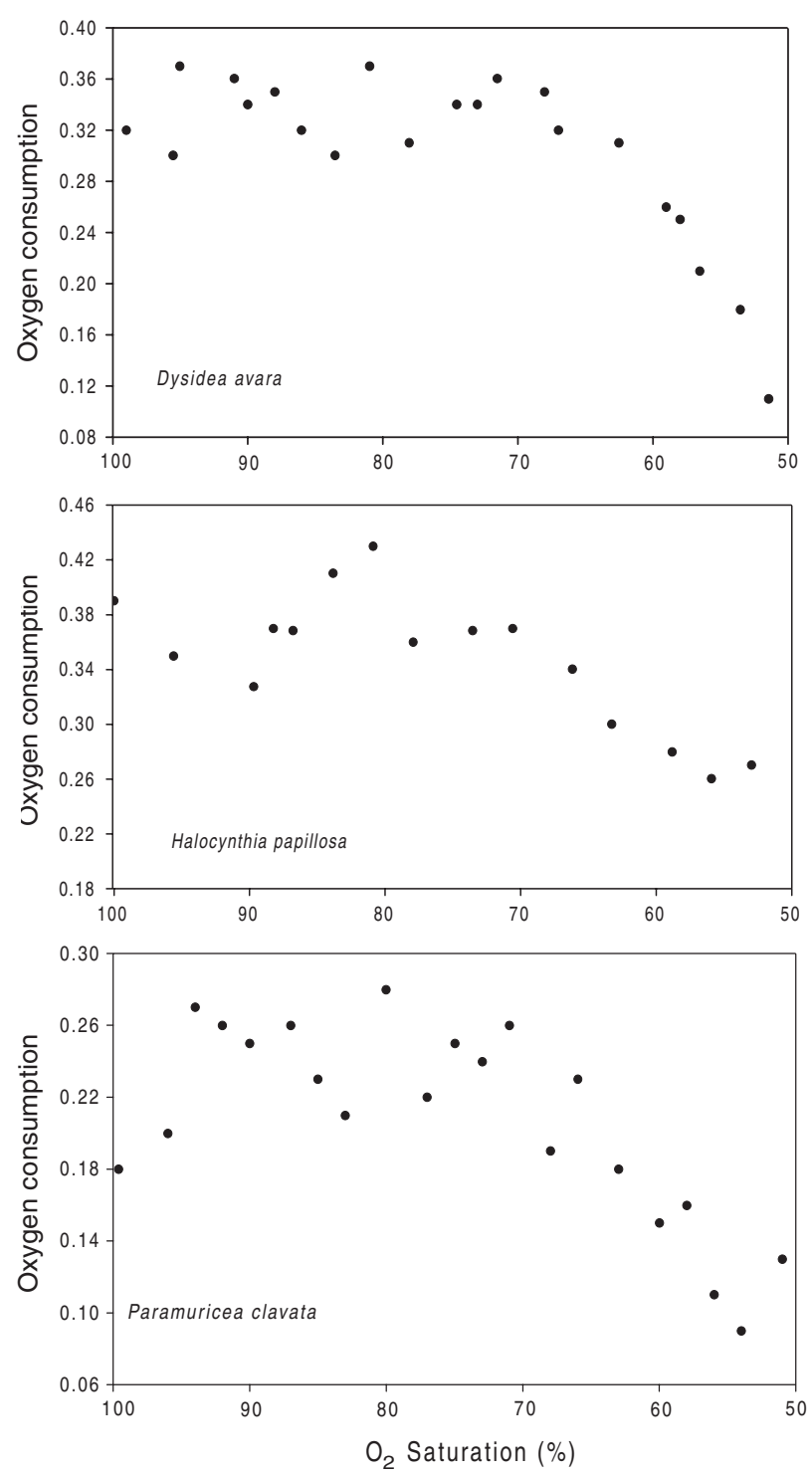

FIG. 4. - Oxygen consumption (in $\mathrm{mg} \mathrm{O}_{2} \mathrm{~g} \mathrm{DW}^{-1} \mathrm{~h}^{-1}$ ) for the 3 species as a function of oxygen saturation percentage: the sponge Dysidea avara, the ascidian Halocynthia papillosa and the gorgonian Paramuricea clavata.

bers; d) the time of acclimation to the chamber condition for the different species; e) the maximum decrease in oxygen concentration without affecting respiration rate; f) the time required to detect changes in concentration of food sources.

By means of injecting a dye (rhodamine b solution) and monitoring the oxygen values within the chambers, a series of examinations were conducted to verify the homogeneity of the water circulation within the chambers. The flushing pump required about 22 seconds for the complete exchange of the water of both chambers. Therefore, to ensure a good renovation of all the water within the chambers, the duration of the flushing (conducted by the 
flushing pump) was programmed to last for $36 \mathrm{sec}-$ onds. This value could be modified through the software of the data logger.

The system and the chambers (one experimental with organism-, and one control) were placed at $15 \mathrm{~m}$ depth by SCUBA divers. At the beginning of each experiment, one specimen was placed on the base of the experimental chamber. We observed that almost all specimens of the three species fully expand within a few minutes. In the few cases that the incubated specimen did not expand fully within a few minutes, it was eliminated from the experiment. The behavior of the incubated specimens, as well as that of conspecifics outside the chambers, was monitored by direct observation at time intervals ranging between $15 \mathrm{~min}$ and 1 hour. The oscula in the sponge species and the syphons in the ascidian species were always open throughout the experiments. The gorgonian species exhibited an expansion and contraction of the polyps similar to that observed in conspecifics and to that previously described from natural populations in the field (Coma et al., 1994; and unpubl. data).

Respiration rates of an individual or colony $(\mathrm{mg}$ $\mathrm{O}_{2}$ biomass $\left.^{-1} \mathrm{~h}^{-1}\right)$ were estimated from each $0.4 \mathrm{mg}$ $\mathrm{O}_{2} \mathrm{l}^{-1}$ decrease in oxygen concentration in the organism chamber during each experiment. The control chamber was used to compensate for ambient oxygen variations such as respiration or oxygen output of planktonic organisms or respiration of bacteria attached to the internal surfaces of the chambers.
Initial oxygen concentration was always saturated or slightly supersaturated. To determine the decrease in oxygen concentration that does not affect respiration rate, several experiments were conducted without the use of the flushing pump and allowing oxygen concentration to decrease to about $50 \%$ from the initial values. These experiments showed two important points: a) that respiration rate estimates during the acclimation period exhibited high variation and, b) that respiration rate estimates were significantly affected by the decrease in oxygen concentration at about $70 \%$ oxygen saturation (Fig. 4a,b,c). Therefore, to avoid the initial variation in respiration rate measurements, most probably due to the period of progressive expansion and acclimatization of the specimens, an acclimation period of 1 hour was chosen. During the period that the incubated specimens were allowed to expand fully, the inlet and oulet apertures of the both experimental and control chambers were not connected, so that the system worked was open-flow. After an acclimation period of 1 hour, inlet and outlet apertures were connected, and the system started to run as closed-flow. In both chambers, oxygen concentration and temperature were recorded continuosly (every 2 minutes by the data logger). The renewal of the water inside both chambers was set to occur at an oxygen concentration drop of $15 \%$. This is a conservative value for the three species that does not affect the estimation of respiration rate.

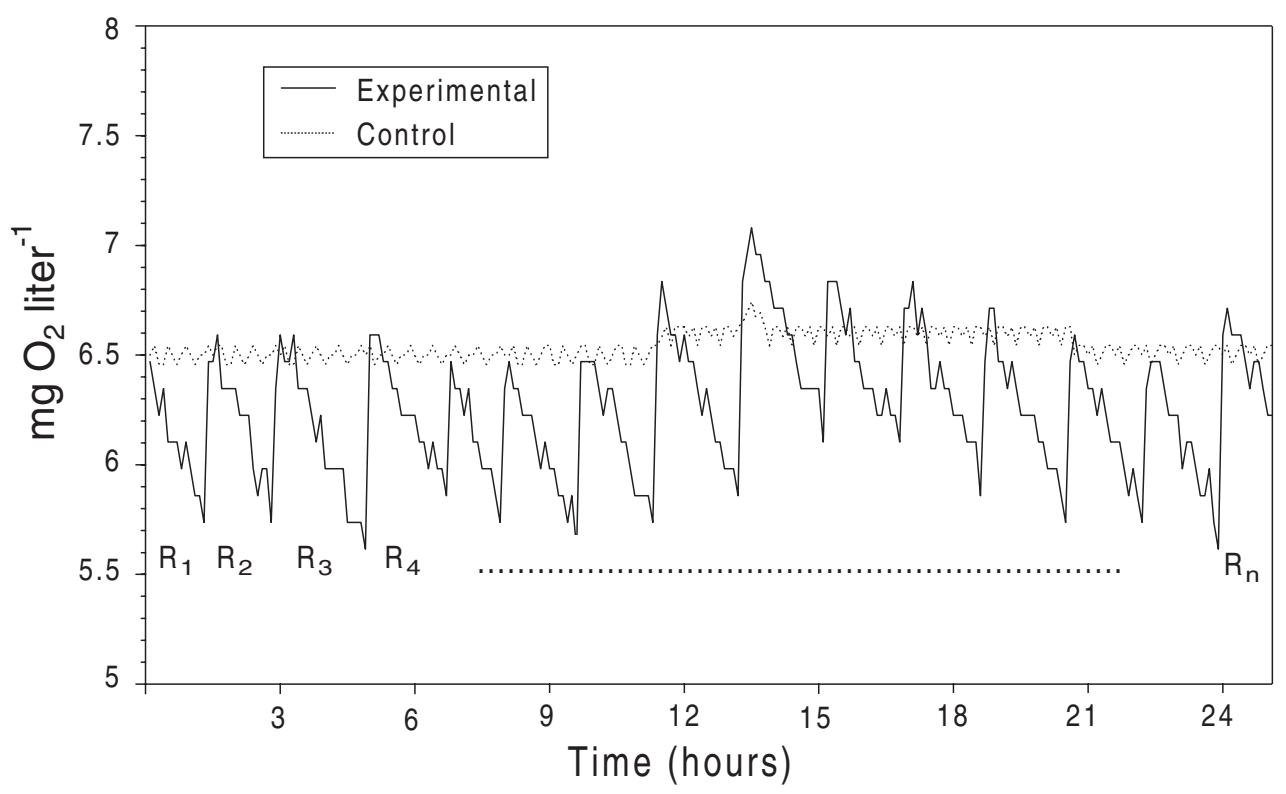

FIG. 5. - Dysidea avara. Example of the oxygen concentration $\left(\mathrm{mg} \mathrm{O}_{2} \mathrm{l}^{-1}\right)$ inside the chambers during a daily cycle. Oxygen values were recorded every 2 minutes in both chambers and water inside both chamber were renewed when oxygen concentration changed $15 \%$ from its initial value. $R_{1} . . R_{n}$ refers to each complete renewal of the water inside the chamber. Experimental: chamber with organism. Control: chamber without organisms. Respiration was determined from decrease in oxygen concentration over time. 
The autonomy of the system was tested by allowing it to work over a 24 hour period because one of the goals was to examine respiration rate over daily cycles. The system was set up with the threshold for the activation of the flushing pump at a 15\% decrease from the initial oxygen concentration and the time period of the flushing programmed to last for 36 seconds and run for a 24 hour cycle. Typically the system flushed the chambers several times per cycle (see Fig. 5 as an example).

Respiration rate values along with the decrease in oxygen concentration within each renewal were calculated (Fig. 5). This allowed a test of whether or not a 15\% drop in initial oxygen concentration affected respiration rates. The test was carried out by comparing, for each renewal within a daily cycle, the first respiration rate estimate (when the organism was subjected to the initial oxygen concentration) with the last one (when the organism was subjected to an almost $15 \%$ drop in oxygen concentration) by means of a student t-test for dependent samples (Sokal and Rohlf, 1995).

The time required to detect changes in concentration of food sources was determined by examining food concentration within both chambers over a 5-6 hour period at 1 hour intervals. The experimental set up followed the previously determined protocol (i.e., placing the specimens within the chamber and allowing an acclimation period of 1 hour during which the inlet and outlet apertures of both the experimental and the control chambers were not connected, so that the system worked as an open-flow one). After the acclimation period and before closing the system, three replicate water samples of $50 \mathrm{ml}$ were collected from the outlet apertures of both the experimental and the control chambers (initial water samples). At this point, inlet and outlet apertures were inlet and outlet apertures were connected and the system worked as a closed flow. Water samples were collected at 1 hour intervals.

The water sample was preserved with formaldehyde $(0.5 \%$ final solution). Subsamples of $15 \mathrm{ml}$ were stained with DAPI and filtered onto $0.2 \mu \mathrm{m}$ filters. The same subsamples were used to count heterotrophic bacteria, Synechoccocus sp., pico- and nanoeukaryotes and heterotrophic nanoflagellates with an epifluoresce microscope (Porter and Feig, 1980). Grazing was calculated from the decrease in prey concentration in the experimental chamber relative to the control chamber. Changes in abundance of food sources over time for the different species
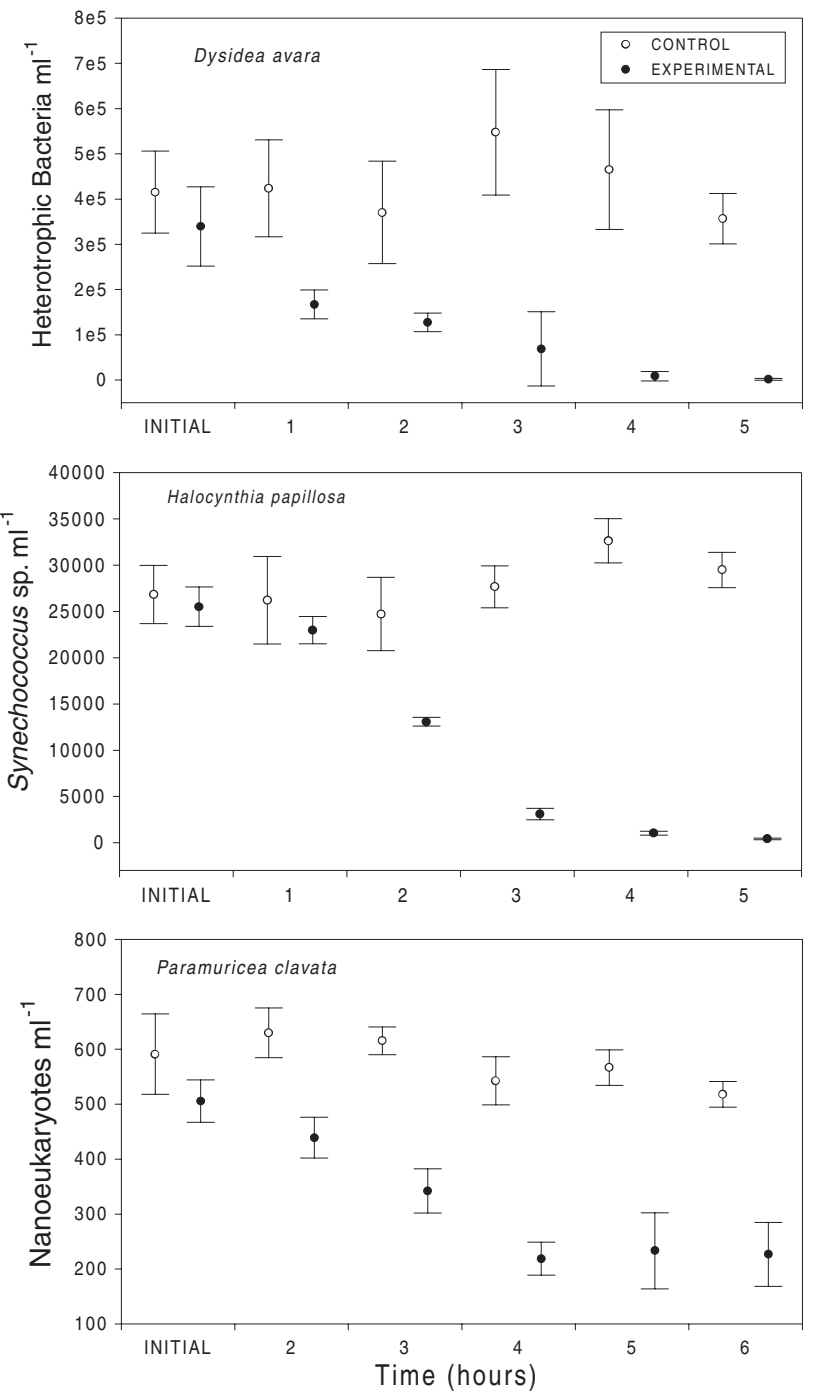

FIG. 6. - Examples of cell concentration (cells $\mathrm{ml}^{-1}$ ) over time for the 3 species. From the top to bottom: a) capture of heterotrophic bacteria by the sponge Dysidea avara, b) capture of Synechococcus sp. by the ascidian Halocynthia papillosa and, c) capture of nanoflagellates by the gorgonian Paramuricea clavata.

within both the experimental and the control chamber were tested using a one-way ANOVA followed by Scheffé's contrast test (Sokal and Rohlf, 1995).

Significant differences were observed in abundance of food sources over time for the 3 species (the sponge Dysidea avara, 1-way ANOVA, $\mathrm{F}_{5,24}=$ 29.88, $\mathrm{p}<0.0001$; the ascidian Halocynthia papillosa, 1-way ANOVA, $\mathrm{F}_{5,24}=102.84, \mathrm{p}<0.0001$ and, the gorgonian Paramuricea clavata, 1-way ANOVA, $\mathrm{F}_{5,30}=39.92, \mathrm{p}<0.0001$; Fig. 6a,b,c). A significant decrease occurred after the first one hour of incubation for the sponge species (Scheffé's contrast test, $\mathrm{p}=0.0015$ ), after the second hour of incubation for the ascidian species (Scheffé's contrast test, $\mathrm{p}=0.005$ ) and, after the third hour of incubation 
for the gorgonian species (Scheffé's contrast test, $\mathrm{p}=0.005$ ) (Fig. 6a,b,c). Significant differences in abundance of food sources over time in the control chambers were only observed for the gorgonian and only after 6 hours of incubation (1-way ANOVA, $\mathrm{F}_{5,30}=5.78, \mathrm{p}=0.0008$, Scheffé's contrast test, $\mathrm{p}=0.005$; the sponge Dysidea avara, 1-way ANOVA, $\mathrm{F}_{5,24}=2.01, \mathrm{p}=0.1134$, and the ascidian Halocynthia papillosa, 1-way ANOVA, $\mathrm{F}_{5,24}=0.75$, $\mathrm{p}=0.5955$; Fig. 6a,b,c). These experiments allowed us to determine the minimum incubation time to detect significant decrease in prey concentration within the experimental chamber. Minimum incubation time varied among the three species and was 1 hour for the sponge, 2 hours for the ascidian and 3 hours for the gorgonian.

One of the main problems of closed systems is the duration of the experiment (Kamler, 1969). Then, minimization of the residence time of the water inside the chambers is a prioritary objective of closed systems. The residence time of the water inside the chamber during feeding experiments was $1 \mathrm{~h}, 2 \mathrm{~h}$ and $3 \mathrm{~h}$ respectively for the sponge, the ascidian and the gorgonian, because this was the minimum time required to detect significant changes in food sources. At the end of this period animals were subjected to an almost 20\% drop in oxygen concentration. The above described respiration experiments showed that a drop 20\% drop in oxygen concentration did not affect respiration rate and animal behavior which is in accordance with the results observed with other species (Fiala-Medioni, 1979, Crisp, 1984, Fabricius and Klumpp, 1995). For the respiration experiments, organims were subjeted to a maximum of a $15 \%$ drop in oxygen concentration because this drop in oxygen concentration already provides several respiration measurements.

This setup allowed us to also examine later the whole spectrum of potential food sources for suspension feeders, including DOC and POM, both live (pico-, nano- and microplankton) and detrital. Sampling, preserving and analysis procedures for all potential food sources as well as calculation procedures and for estimating feeding rates of the three species over a annual cycle are carefully described in Ribes et al., 1998, 1999a,b).

\section{DISCUSSION}

There are several problems related with the use of closed systems to conduct studies of metabolism, such as the decline in oxygen concentration and the accumulation of metabolites, the formation of oxygen gradients as a result of water stagnation, and inconsistent respiration readings obtained in relation to the duration of the experiment (Kamler, 1969). During the last years, several studies have optimizated the use of closed systems and have shown that they represent an important tool to examine in situ change in oxygen concentration related to benthic communities (Smith et al., 1972; Zeitzschel and Davies, 1978; Hall et al., 1979; Svoboda and Ott, 1983; Patterson et al., 1991; Glud et al., 1995). As in the mentioned works, we have described a system which solves the potential problems of a closed system and allows us to perform feeding studies. The formation of oxygen gradients has been solved by the continuous flow forced by both flow pumps. Oxygen concentration decrease which can affect the behavior of the organism (Herreid, 1980) and the accumulation of metabolites were avoided by the automatic flushing system which periodically renewed the water of both chambers and that can be modified depending on the studied species. Therefore, this autonomous operating system is a useful tool to study metabolic activity of benthic organisms (both production and consumption of oxygen) and feeding rates under, as close as possible, natural conditions.

We are aware that an important parameter, water movement, which is known to affect the energetic of aquatic organisms (Boynton et al., 1981; Patterson and Sebens, 1989; Patterson et al., 1991) has not been taken into account. This study was limited to a single flow speed which is rather low $(1.2 \mathrm{~cm} / \mathrm{s})$. However, the described apparatus may allow the user to have different flow speeds by modifying the voltage converter. This modification could easily provide a range of voltage to the pump from 3 to 12 $\mathrm{V}$ that would permit a wide range of flow speeds.

Field techniques to analyze the natural range of potential food sources have not received much attention other than for phytoplankton and zooplankton assessment. This is due to the difficulties involved in the elaboration of specific protocols for each of the different components of the seston. Some of these protocols are of current use by other fields such as microbiology. However, the compilation and standardization of these methods for a relatively small water samples (such as those required to analyse the water whithin the chambers, Ribes et al., 1998, 1999a,b) may facilitate the performance of feeding experiments to examine natural diets and feeding rates. 
The development of both experimental sampling devices and analytical protocols is a necessary component of field research, even though funding is notoriously difficult to obtain for it and the time consumption for the development of technical preparations is discouraging. However, without the development of new methodological field approaches, our progress in understanding the functioning and dynamics of littoral marine ecosystems is constrained because laboratory experiences can not simulate the extremely diversified biological processes that work in natural ecosystems.

\section{ACKNOWLEDGEMENTS}

The manuscript was improved by the comments of Fenny Cox. We would like to thanks the assistance of Mikel Zabala, Josep-Maria Llenas and Loïc de Maissonneuve. Support for this work was provided by a RED research contract from the "Generalitat de Catalunya" to R.C., by a postdoctoral fellowship from the "Ministerio de Educación y Cultura" to M.R., by PETRI grant PTR94-0119, by DGICYT grant PB98-0456-C03-01 and by a LEA project.

\section{REFERENCES}

Ayukai, T. - 1995. Retention of phytoplankton and planktonic microbes on coral reefs within the Great Barrier Reef, Australia. Coral Reefs, 14: 141-147.

Azam, F.T., J.G. Fenchel, J.S. Field, L.A. Gray and F. Meyer-Reil Thingstad. - 1983. The ecological role of water-column microbes in the sea. Mar. Ecol. Prog. Ser., 10: 257-263.

Boynton, W.R., W.M. Kemp, C.G. Osborne, K.R. Kaumeyer and M.C.Jenkins. - 1981. Influence of water circulation rate on in situ measurements of benthic community respiration. Mar. Biol., 65: 185-190.

Burkill, P.H., E.S. Edwards, A.W.G. John and M.A. Sleigh. - 1993. Microzooplankton and their herbivorous activity in the northeastern Atlantic Ocean. Deep Sea Res.II., 40: 479-493.

Cloern, J.E. - 1982. Does the benthos control phytoplankton biomass in South San Francisco Bay? Mar. Ecol. Prog. Ser., 9: 191-202.

Coma, R., J.M. Gili, M. Zabala and T. Riera. - 1994. Feeding and prey capture cycles in the aposymbiotic gorgonian Paramuricea clavata. Mar. Ecol. Prog. Ser., 155: 257-270.

Coma, R., M. Ribes, J.M. Gili and M. Zabala. - 1998. An energetic approach to the study of life-history traits of two modular colonial benthic invertebrates. Mar. Ecol. Prog. Ser., 162: 89-103.

Crisp, D.J. - 1984. Energy flow measurements. In: N.A. Holme and A.D. McIntyre (eds), Methods for the study of marine benthos, pp. 284-372. IBP Handbook 16. Balckwell Scientific Publications. Oxford.

Fabricius, K.E. and D.W. Klumpp. - 1995. Widespread mixotrophy in reef-inhabiting soft corals: The influence of depth, and colony expansion and contraction on photosynthesis. Mar. Ecol. Prog. Ser., 125: 195-204.

Fiala-Medioni, A. - 1979. Effects of oxygen tension on pumping, filtration and oxygen uptake in the ascidian Phallusia mammillata. Mar. Ecol. Prog. Ser., 1: 49-53.

Gasol, J.M. and P.A. del Giorgio. - 2000. Using flow cytometry for counting natural planktonic bacteria and understanding the structure of planktonic bacterial communities, Sci. Mar., 64: 197-224.

Gili J.M. and R. Coma. - 1998. Benthic suspension feeders: Their paramount role in littoral marine food webs. Trends Ecol. Evol., 13: 316-321.

Glud, R.N., J.K. Gundersen, N.P. Revsbech, B.B. Jørgensen and M. Huettel. - 1995. Calibration and performance of the stirred flux chamber from the benthic lander Elinor. Deep Sea Res., 42: 1029-1042.

Hall, C.A.S., N. Tempel and B.J. Peterson. - 1979. A benthic chamber for intensely metabolic lotic systems. Estuaries, 2: 178-183.

Herreid, C.F. II. - 1980. Hypoxia in invertebrates. Comp. Biochem. Physiol., 67A: 311-320.

Jørgensen, C.B. - 1966. Biology of suspension feeding. Pergamon Press. Oxford.

Kamler, E. - 1969. A comparison of the close-bottle and flowing water methods for measurement of respiration in aquatic invertebrates. Pol. Arch. Hydrobiol., 16: 31-49.

Kanwisher, J. - 1959. Polarographic oxygen electrode. Limnol. Oceanogr. 4: 210-217.

Lasker, H.R. - 1981. A comparison of the particulate feeding abilities of three species of gorgonian soft coral. Mar. Ecol. Prog. Ser., 5: 61-67.

Leversee, G.J. - 1976. Flow and feeding in fan-shaped colonies of the gorgonian coral, Leptogorgia. Biol. Bull., 151: 344-356.

Lucas, A. - 1996. Bioenergetics of aquatic animals. T.J. Press. Great Britain.

Patterson, M.R. and K.P. Sebens. - 1989. Forced convection modulates gas exchange in cnidarians. Proc. Natl. Acad. Sci., 86: 8833-8836.

Patterson, M.R., K.P. Sebens and R.R. Olson. - 1991. In situ measurements of flow effects on primary production and dark respiration in reef corals. Limnol. Oceanogr., 36: 936-948.

Petersen, J.K. and H.U. Riisgård. - 1992. Filtration capacity of the ascidian Ciona intestinalis and its grazing impact in a shallow fjord. Mar. Ecol. Prog. Ser., 88: 9-17.

Pile, A.J., M.R. Patterson, M. Savarese, V.Y. Chernykh and V.A. Fialkov. - 1997. Trophic effects of sponge feeding within Lake Baikal's littoral zone. II. Sponge abundance, diet, feeding efficiency, and carbon flux. Limnol. Oceanogr., 42: 178-184.

Pile, A.J., M.R. Patterson and J.D. Witman. - 1996. In situ grazing on plankton $<10 \mu \mathrm{m}$ by the boreal sponge Mycale lingua. Mar. Ecol. Prog. Ser., 141: 95-102.

Platt, T., D.V. Subba Rao and B. Irwin 1983. - Photosynthesis of picoplankton in the oligotrophic ocean. Nature, 301: 702-704.

Porter, K.G. and Y.S. Feig. - 1980. The use of DAPI for identifying and counting aquatic microflora. Limnol. Oceanogr., 25: 943-948

Ribes, M., R. Coma and J.M. Gili. - 1998. Seasonal variation of in situ feeding rates by the temperate ascidian Halocynthia papillosa. Mar. Ecol. Prog. Ser., 175: 201-213.

Ribes, M., R. Coma and J.M. Gili. - 1999a. Natural diet and grazing rate of the temperate sponge Dysidea avara (Demospongiae, Dendroceratida) throughout an annual cycle. Mar. Ecol. Prog. Ser., 176: 179-190.

Ribes, M., R. Coma and J.M. Gili. - 1999b. Heterogeneous feeding in benthic suspension feeders: the natural diet and grazing rate of the temperate gorgonian Paramuricea clavata (Cnidaria: Octocorallia) over a year cycle. Mar. Ecol. Prog. Ser., 183: 125-137.

Riisgård, H.U. and P.S. Larsen (in press). Review of zoobenthic filter-feeding, an ecophysiological approach. J. Sea. Res.

Rubenstein, D.I. and M.A.R. Koehl - 1977. The mechanism of filter feeding: some theoretical considerations. Am. Nat., 111: 981-994.

Sebens, K.P. - 1987. Coelenterata. In: T.J. Pandian and F.J. Vernberg (eds), Animals Energetics, pp. 55-120. Academic Press.

Sherr, E.B, and B.F. Sherr. - 1991. Planktonic microbes: Tiny cells at the base of the ocean's food webs. Trends Ecol. Evol. 6: 50-54.

Shumway, S.E. - 1982. Oxygen consumption in oysters: an overview. Mar. Biol. Letters, 3: 1-23.

Smith, K.L., K.A. Burns and J.M. Teal. - 1972. In situ respiration of benthic communities in Castle Harbor, Bermuda. Mar Biol., 12: 196-199.

Sokal, R.R. and F.J. Rohlf. - 1995. Biometry. The principles and practice of statistics in biological research, 3nd edn. Freeman. New York. 
Stockner, J.G. and N.J. Antia. - 1986. Algal picoplankton from marine and freshwater ecosystems: a multidisciplinary perspective. Can. J. Fish. Aq. Sci., 43: 2472-2503.

Svoboda, A. - 1978. In situ monitoring of oxygen production and respiration in cnidaria with and without zooxanthellae. In: D.S. McLusky and A.J. Berry (eds), Physiology and behaviour of marine organisms, pp. 75-82. Proceedings of the 12th European Symposium on Marine Biology Stirling, Scotland. Pergamon Press. Oxford.

Svoboda, A. and J. Ott. - 1983. In situ measurement of community metabolism in littoral marine systems. In: E. Gnaiger and $\mathrm{H}$.
Forstner (eds), Polarographic Oxygen Sensors, pp. 285-297. Springer-Verlag. Berlin.

Tengberg, A. and others. - 1995. Benthic chamber and profiling landers in oceanography - A review of design, technical solutions and functioning. Prog. Oceanogr., 35: 253-294.

Tremblay, J.E. and L. Legendre. - 1994. A model for the size-fractioned biomass and production of marine phytoplankton. Limnol. Oceanogr., 39: 2004-2014.

Zeitzschel, B. and J.M. Davies. - 1978. Benthic growth chambers. Rapp. P.- V. Réun. Cons. Int. Explor. Mer, 173: 31-42.

APPENDIX I. Program to control the functioning the autonomous system by means of the data logger (Tattletale Model 4A, Onset Computer Corporation). Written in Visual Basic.

\author{
ASM \&H9A, DW 8,0 \\ 1 IF F $>=1$ GOTO 70 \\ 20 RATE 1 \\ 30 PCLR 0 \\ $40 \mathrm{~W}=65500$ \\ 50 SLEEP 0 \\ 60 SLEEP $\left(\mathrm{H}^{*} 100\right)$ \\ 70 IF PIN(0)=1 GOTO 340 \\ 80 IF $\mathrm{F}>=\mathrm{G}$ GOTO 340 \\ 90 ONERR 340 \\ 94 RTIME \\ 95 STIME A \\ 96 IF $A<5 \quad A=128$ \\ 97 STORE X,\#2,A \\ 99 PRINT A \\ 100 BURST X,5,2 \\ $101 \mathrm{FOR} E=0$ TO 4 \\ 102 PRINT CHAN(E) \\ 103 NEXT E \\ $110 \mathrm{~F}=\mathrm{F}+1$ \\ $120 \mathrm{M}=\mathrm{X}-8$ \\ $130 \mathrm{~K}=\mathrm{GET}(\mathrm{M}, \# 2)$ \\ 132 IF N=1 W=K
}

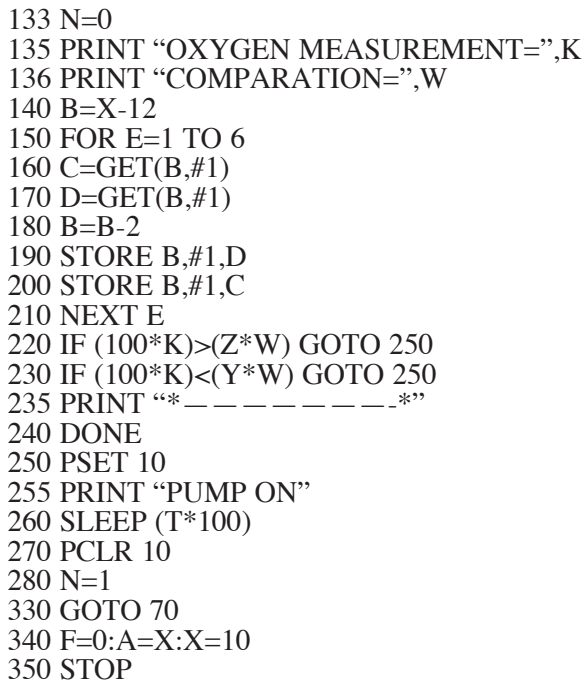

